\title{
Study comparing the hypolipidemic effects of Terminalia Arjuna with Rosuvastatin on triglyceride and high density lipoprotein- cholesterol levels
}

\author{
Ved Prakash
}

Assistant Professor, Dept. of Pharmacology, Hind Institute of Medical Sciences, Safedabad Barabanki, Uttar Pradesh, India

*Corresponding Author: Ved Prakash

Email: sonivedgmc@gmail.com

\begin{abstract}
Introduction: Due to substantial increase of coronary heart disease, a need for identifying and correcting the conventional risk factors like hypertension, diabetes mellitus, smoking and hyperlipidemia has been emerged, as controlling them not only prevents the formation of atheromatous plaque but also slows down its progression and even promotes regression.

AIM: Comparing the effects of Terminalia arjuna with Rosuvastatin on triglycerides and high density lipoprotein cholesterol in dyslipidemic patients of either sex.

Materials and Methods: A 12 weeks open prospective randomized controlled study, enrolling 60 patients of dyslipidemia was conducted. Patients were distributed in two groups of 30 each. Group A was given Rosuvastatin (10mg) once daily and group B was given Terminalia arjuna (500mg) twice daily. Triglyceride and HDL-C levels were done at baseline and after 4, 8 and 12 weeks of starting the treatment and data was statistically analyzed.

Results: Greater reduction in mean Triglyceride level was demonstrared with Terminali arjuna as compared to Rosuvastatin $(-35.23 \pm 37.59$ vs $-13.30 \pm 6.64),(-51.66 \pm 48.67$ vs $-25.23 \pm 11.29)$ and $(-60.63 \pm 49.93$ vs- $-35.16 \pm 14.76)$ at 4,8 and 12 weeks respectively and the difference between both the groups was statistically significant $(\mathrm{p}<0.05)$ at all the visits. Increase in mean HDL-C level in T.arjuna group as compared to Rosuvastatin group was more $(2.37 \pm 2.20 \mathrm{vs} 1.97 \pm 1.40)$ at 4 weeks but was slightly less $(3.43 \pm 2.88$ vs $3.53 \pm 2.31)$ and $(4.37 \pm 2.76$ vs $4.77 \pm 2.40)$ at 8 and 12 weeks. On comparing difference was found to be statistically non-significant.

Conclusion: Rosuvastatin and Terminalia arjuna both are effective hypolipidemic agents causing significant decrease in triglyceride and increase in high density lipoprotein cholesterol. Terminalia arjuna had showed greater reduction triglyceride and was found to be safe.
\end{abstract}

Keywords: Rosuvastatin, Terminalia arjuna, High density lipoprotein cholesterol, Triglyceride.

\section{Introduction}

The term "cardiovascular disease" (CVD) is used for group of disorders of heart and blood vessels. CVD is often thought to be a problem of wealthy, industrialized nations but it is the leading cause of death worldwide. The accelerating rates of unrecognized and inadequately addressed CVD and related chronic diseases in both men and women in low and middle income countries are cause for immediate action. ${ }^{1}$

It is expected that by 2020 , CVD would prevail as the leading cause of death and disability over infectious diseases globally. In 2008, a study reported that India alone is burdened with approximately $25 \%$ of cardiovascular-related deaths and would serve as a home to more than $50 \%$ of the patients with heart ailments worldwide within next 15 years. ${ }^{2}$

There is a need for identifying and correcting the conventional risk factors like hypertension, diabetes mellitus, smoking, hyperlipidemia, tobacco consumption and central obesity at much younger age. ${ }^{3}$ A retrospective study analyzed the association of major modifiable risk factors among patients with coronary artery disease (CAD). Among the risk factors assessed, dyslipidemia, smoking, hypertension and diabetes were associated with CAD with decreasing order of prevalence. ${ }^{4}$

Modern primary care practitioners spend considerable time and effort on preventative medicine. Diagnosing and managing hyperlipidemia as a way to 
prevent CVD is a common activity for primary care physicians. 5

Current ATP III guidelines recommend lipid screening in all adults $>20$ years of age. The screen should include a fasting lipid profile (TC, Tg, LDL-C, and HDL-C) repeated every 5 years. ${ }^{6}$

Although treatment of hyperlipidemia in the context of prevention of CVD has largely been focused on the management of total plasma and LDL$\mathrm{C}$ levels, a number of recent studies have reported associations between Tg levels and CVD. ${ }^{6}$

Statins (HMG-CoA reductase inhibitors) are used widely for the treatment of hypercholesterolemia. They inhibit HMG-CoA reductase competitively, reduce LDL levels more than other cholesterollowering drugs, and lower triglyceride levels in hypertriglyceridemic patients. ${ }^{7}$

Statins are considered very effective in reducing cardiovascular morbidity and mortality in high-risk patients. However, although adherence to statins improves morbidity and mortality, it remains suboptimal. One of the most important causes of nonadherence is the so-called statin intolerance, mainly because of muscle-related symptoms. These symptoms most often consist of myalgia unaccompanied by significant creatine kinase (CK) elevations. Less often, myositis or rhabdomyolysis develops. Other side effects of statins include- hepatotoxicity, hemorrhagic stroke, cognitive decline, peripheral neuropathy, DM, insomnia, tendinitis, arthralgia, arthritis and cataract. ${ }^{8}$

Since Ayurveda has been the science of life as a whole, and its percepts have governed to a greater or lesser degree the choice and style of foods in India for millennia, the scientific and nutritional exploration of the medicinal effects as referred to in this indigenous medical sciences could bring immense health benefits. ${ }^{9}$

Plants have been a major source of drugs in modern medicine for the last two centuries. In Ayurvedic system of medicine, one such medicinal plant is Terminalia arjuna (Roxb. Combretaceae family), which is known as arjuna in many Indian languages. It has been used as a medicinal plant since the period of Vedas. The stem bark of the plant is mainly used for medicinal purposes. It is mentioned to be a cardiac tonic (Hrdya). It has been used in powder form, decoction and Ksheerpak (boiled in water and milk) as cardioprotective. Many important biologically active chemical compounds have been isolated from $T$. arjuna. These include triterpenoids (like, arjunolic acid, arjunic acid, arjungenin, arjunoglucoside),tannins (ellagic acid, gallic acid), flavonoids (leucocyanidin, luteolin) and minerals (magnesium, calcium, zinc and copper).Over the last few decades, there has been a resurgence of scientific interest in exploring the pharmacological activities of the plant using modern methodologies. $^{10}$

A number of experimental and clinical studies have been conducted to explore therapeutic potential of Terminalia arjuna in cardiovascular ailments specially in patients of CHD. ${ }^{11}$

T. arjuna tree bark powder has significant antioxidant action. In addition, it has also been reported to have hypocholesterolaemic effect. ${ }^{6}$

This may be due to interference with the absorption of dietary cholesterol as well as bile acid from the intestine, increased elimination of the faecal sterols and increased stimulation of bile acid synthesis may lead to increased utilization of cellular free cholesterol. Prolonged administration of T. arjuna did not show any adverse effects on renal, hepatic and hematological parameters. ${ }^{6}$

In this study we are evaluating the effect of Terminalia arjuna on $\mathrm{Tg}$ and HDL-C levels in comparison with Rosuvastatin.

\section{Material s and Methods}

The present study was conducted in Pharmacology department in association with department of Medicine and Pathology, enrolling 60 patients of dyslipidemia coming to outdoor department of medicine. The patients were selected in the study on the basis of the following inclusion and exclusion criteria.

\section{Inclusion criteria}

Patients of $>20$ years of either sex, with dyslipidemia, having $\mathrm{Tg} \geq 150 \mathrm{mg} / \mathrm{dl}$, HDL $<50 \mathrm{mg} / \mathrm{dl}$ in women and $\mathrm{HDL}<40 \mathrm{mg} / \mathrm{dl}$ in men. 


\section{Exclusion criteria}

Patients with hepatic or renal failure, congenital heart disease/ rheumatic heart disease and pregnant women.

12 weeks, open prospective randomized study enrolling 60 patients of dyslipidemia, fulfilling the inclusion criterias and having none of the exclusion criteria, after taking written informed consent was conducted with the permission of the institutional ethical committee and required procedures were performed according to the declaration of Helsinki. A detailed history and clinical examination of all the patients was done and recorded and later on a watch was kept on any undesirable new symptoms that might appear during the study period. Patients were advised to stop the drug and report immediately if he/she feels any undesirable symptoms during the course treatment.

These patients were randomly divided into age and sex matched two groups i.e. Group A and group B of 30 patients each and were advised to have low fat diet, avoid alcohol intake and follow lifestyle modification like regular exercise and quit smoking. Baseline characteristics i.e. gender, past and personal history was statistical analysed using chi-square test $\left(\chi^{2}\right)$ and for age group student ' $t$ ' was used. Group A- patients were given Rosuvaststin $10 \mathrm{mg}$ once daily at bed time. Group B- patients were given Terminalia arjuna 500 mg twice daily. Patients Tg and HDL-C levels were evaluated and recorded at baseline, 4, 8, and 12 weeks. Then the baseline values were compared with the values at 4,8 and 12 weeks, within the group and also between both the groups, and then evaluated. Data was expressed as mean \pm standard deviation (SD). For $\mathrm{Tg}$ and HDL-C parameters student ' $\mathrm{t}$ ' test was used. Paired ' $\mathrm{t}$ ' test was used for intra-group comparison, evaluating the effect of treatment. Unpaired ' $t$ ' test was used for inter-group comparison, for evaluating the effect of both the drugs. P value of less than 0.05 was considered as statistically significant.

\section{Results}

Baseline comparison

According to gender/age: $13(43.33 \%)$ females and $17(56.67 \%)$ males in group A and, $14(46.7 \%)$ females and $16(53.3 \%)$ males in group B were included. For group A patients mean for age was $57.37 \pm 8.31$ years and for group B patients was $54.87 \pm 7.33$ years. Statistical analysis of both age and gender showed that the difference between the two groups was not statistically significant ( $p>0.05$ ).

Past history: 6, 22 and 9 patients had past history of CAD, Hypertension and Diabetes mellitus respectively, while absent in 24, 08 and 21 patients respectively in group A. In group B 8, 20 and 7 patients had past history of CAD, Hypertension and Diabetes mellitus respectively, while absent in 22, 10 and 23 patients respectively. Difference was nonsignificant. ( $p>0.05)$.

Personal history: In group A, 7 patients were alcoholics and 22 patients had sedentary lifestyle and no patient had history of smoking,. While in group B, 8 patients were alcoholics, 23 patients had sedentary lifestyle and 1 patient was smoker,. The difference between group A and B was non-significant, hence groups were comparable ( $\mathrm{p}>0.05)$.

Table 1: Baseline characteristic comparison

\begin{tabular}{|c|c|c|c|c|c|}
\hline & Mean age (years) & \multicolumn{2}{|c|}{ Gender } & \multicolumn{2}{|c|}{ Lipid profile } \\
\hline & & Male & female & $\mathrm{Tg}$ & HDL-C \\
\hline $\begin{array}{c}\text { Rosuvastatin } \\
\text { Group A } \\
\text { N=60 }\end{array}$ & $57.37 \pm 8.31$ & 17 & 13 & $167.30 \pm 18.46$ & $37.60 \pm 3.03$ \\
\hline $\begin{array}{c}\text { Terminalia arjuna } \\
\text { Group B } \\
\text { N=60 }\end{array}$ & $54.87 \pm 7.33$ & 16 & 14 & $206.10 \pm 67.86$ & $42.70 \pm 7.44$ \\
\hline$p$ value & $>0.05$ & & 05 & & \\
\hline
\end{tabular}


Table 2: Comparison of change in mean triglyceride ( $\mathrm{Tg}$ ) level in group A (Rosuvastatin) patients

\begin{tabular}{|c|c|c|c|c|c|c|c|}
\hline Time interval & Mean \pm SD & Mean change \pm SD & SE Mean & t & df & P & Sig. \\
\hline Baseline & $167.30 \pm 18.46$ & - & - & - & - & - & - \\
\hline 4 weeks & $154.00 \pm 15.92$ & $-13.30 \pm 6.64$ & 1.21 & 10.96 & 29 & 0.000 & HS \\
\hline 8 weeks & $142.07 \pm 14.05$ & $-25.23 \pm 11.29$ & 2.06 & 12.24 & 29 & 0.000 & HS \\
\hline 12 weeks & $132.13 \pm 12.11$ & $-35.16 \pm 14.76$ & 2.69 & 13.05 & 29 & 0.000 & HS \\
\hline
\end{tabular}

As is evident from the table 2, the mean change \pm SD in Tg level with Rosuvastatin treatment was $-13.30 \pm 6.64$, $25.23 \pm 11.29$ and $-35.16 \pm 14.76$ at the end of 4,8 and 12 weeks respectively. The analysis of decrease in mean $\mathrm{Tg}$ level was found to be statistically highly significant $(\mathrm{p}<0.001)$ at 4,8 and 12 weeks.

Table 3: Comparison of change in mean triglyceride (Tg) level in group B (T. Arjuna) patients

\begin{tabular}{|c|c|c|c|c|c|c|c|}
\hline Time interval & Mean \pm SD & Mean change \pm SD & SE Mean & T & df & P & Sig. \\
\hline Baseline & $206.10 \pm 67.86$ & - & - & - & - & - & - \\
\hline 4 weeks & $170.87 \pm 45.85$ & $-35.23 \pm 37.59$ & 6.86 & 5.13 & 29 & 0.000 & HS \\
\hline 8 weeks & $154.43 \pm 40.34$ & $-51.66 \pm 48.67$ & 8.88 & 5.81 & 29 & 0.000 & HS \\
\hline 12 weeks & $145.47 \pm 37.60$ & $-60.63 \pm 49.93$ & 9.12 & 6.65 & 29 & 0.000 & HS \\
\hline
\end{tabular}

As is evident from the table 3, the mean change \pm SD in Tg level with T.arjuna treatment was $-35.23 \pm 37.59$, $51.66 \pm 48.67$ and $-60.63 \pm 49.93$ at the end of 4,8 and 12 weeks respectively. The analysis of decrease in mean $\mathrm{Tg}$ level was found to be statistically highly significant $(\mathrm{p}<0.001)$ at 4,8 and 12 weeks.

Table 4: Comparison of change in mean triglyceride (Tg) level between group A (ROSUVASTATIN) and group B (T. Arjuna)

\begin{tabular}{|c|c|c|c|c|c|c|c|c|c|}
\hline Time interval & Group & Mean \pm SD & $\begin{array}{c}\text { Mean change } \\
\text { 土 SD }\end{array}$ & $\begin{array}{c}\text { Mean } \\
\text { difference }\end{array}$ & $\begin{array}{c}\text { SE } \\
\text { difference }\end{array}$ & $\mathbf{t}$ & Df & $\mathbf{P}$ & Sig. \\
\hline \multirow{2}{*}{ Baseline } & A & $167.30 \pm 18.46$ & - & - & - & - & - & - & - \\
\hline & $\mathrm{B}$ & $206.10 \pm 67.86$ & - & - & - & - & - & - & - \\
\hline \multirow{2}{*}{$\begin{array}{c}\text { After } \\
4 \text { weeks }\end{array}$} & $\mathrm{A}$ & $154.00 \pm 15.92$ & $-13.30 \pm 6.64$ & \multirow{2}{*}{21.93} & \multirow{2}{*}{6.97} & \multirow{2}{*}{3.15} & \multirow{2}{*}{58} & \multirow{2}{*}{0.003} & \multirow{2}{*}{ S } \\
\hline & $\mathrm{B}$ & $170.87 \pm 45.85$ & $-35.23 \pm 37.59$ & & & & & & \\
\hline \multirow{2}{*}{$\begin{array}{c}\text { After } \\
8 \text { weeks }\end{array}$} & $\mathrm{A}$ & $142.07 \pm 14.05$ & $-25.23 \pm 11.29$ & \multirow{2}{*}{26.43} & \multirow{2}{*}{9.12} & \multirow{2}{*}{2.89} & \multirow{2}{*}{58} & \multirow{2}{*}{0.005} & \multirow{2}{*}{ S } \\
\hline & $\mathrm{B}$ & $154.43 \pm 40.34$ & $-51.66 \pm 48.67$ & & & & & & \\
\hline \multirow{2}{*}{$\begin{array}{c}\text { After } \\
12 \text { weeks }\end{array}$} & $\mathrm{A}$ & $132.13 \pm 12.11$ & $-35.16 \pm 14.76$ & \multirow{2}{*}{25.47} & \multirow{2}{*}{9.50} & \multirow{2}{*}{2.68} & \multirow{2}{*}{58} & \multirow{2}{*}{0.010} & \multirow{2}{*}{ S } \\
\hline & $\mathrm{B}$ & $145.47 \pm 37.60$ & $-60.63 \pm 49.93$ & & & & & & \\
\hline
\end{tabular}

As evident from table- 4 and fig. 1, T.arjuna leads to greater reduction in mean Tg level than Rosuvastatin ($35.23 \pm 37.59$ vs $-13.30 \pm 6.64),(-51.66 \pm 48.67$ vs $-25.23 \pm 11.29)$ and $(-60.63 \pm 49.93$ vs $-35.16 \pm 14.76)$ at 4,8 and 12 weeks respectively. The difference between both the groups was statistically significant $(\mathrm{p}<0.05)$ at 4,8 and 12 weeks. 


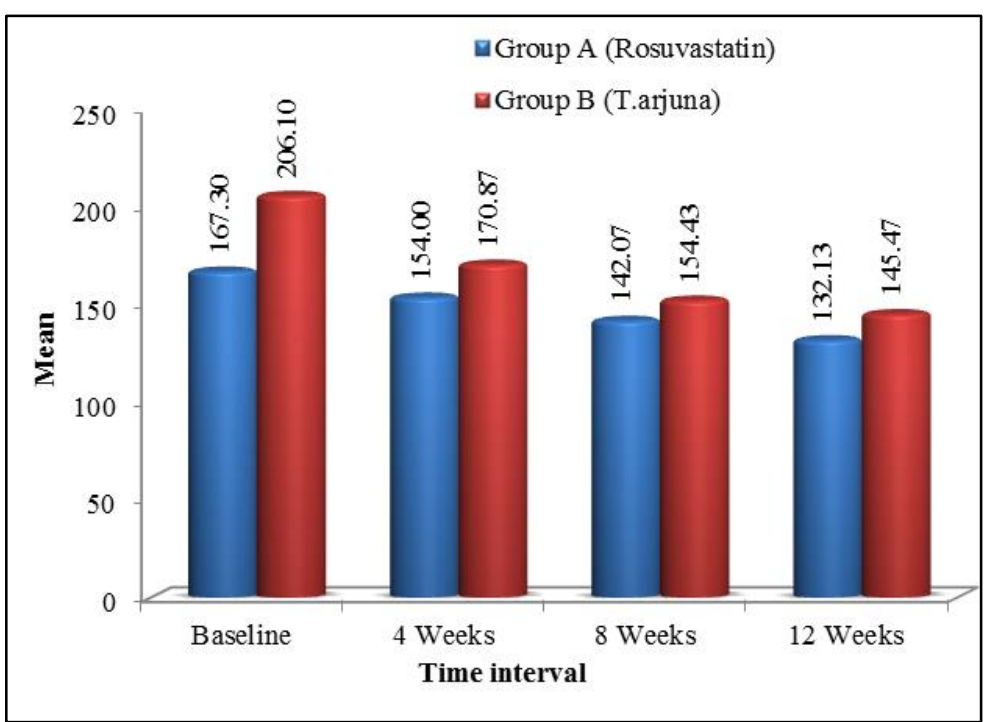

Fig. 1: Change in mean Triglyceride level

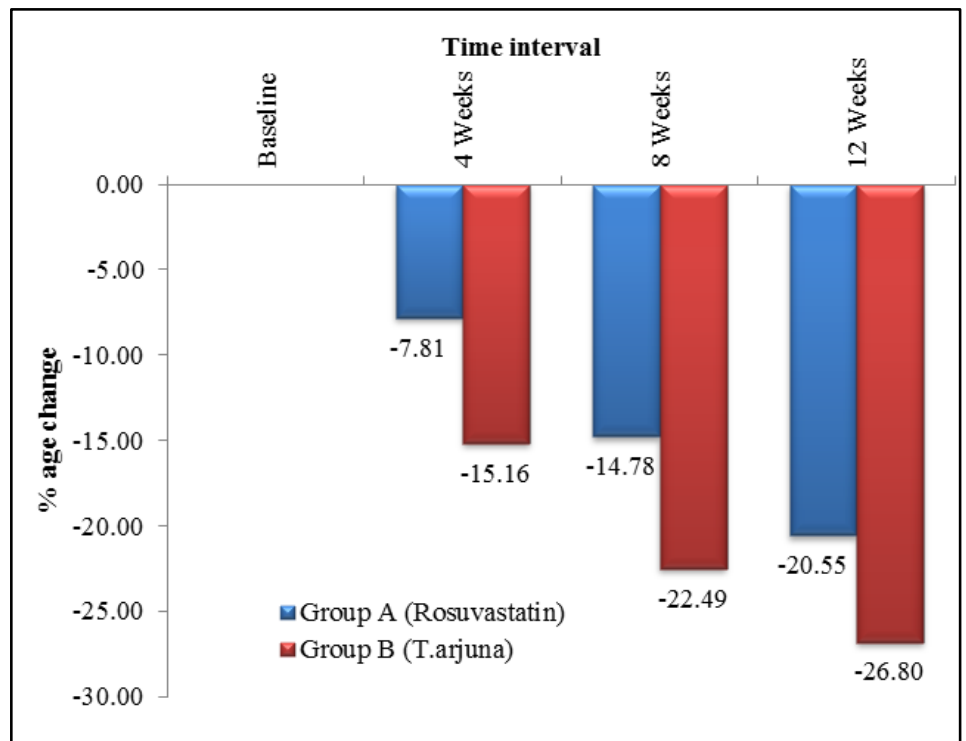

Fig. 2: Percentage change in mean Triglyceride level

T. Arjuna leads to greater reduction in percentage mean $\mathrm{Tg}$ level than Rosuvastatin $(-15.16 \pm 12.24 \%$ vs $7.81 \pm 3.55 \%),(-22.49 \pm 15.05 \%$ vs $-14.78 \pm 5.84 \%)$ and $(-26.80 \pm 14.75 \%$ vs $-20.55 \pm 7.41 \%)$ at 4,8 and 12 weeks respectively. The difference between both the groups was statistically significant $(\mathrm{p}<0.05)$ at 4,8 and 12 weeks.

Table 5: Comparison of change in mean high density lipoprotein cholesterol (HDL-C) LEVEL OF GROUP A (Rosuvastatin) Patients

\begin{tabular}{|c|c|c|c|c|c|c|c|}
\hline Time interval & Mean \pm SD & $\begin{array}{c}\text { Mean change } \\
\pm \text { SD }\end{array}$ & $\begin{array}{c}\text { SE } \\
\text { Mean }\end{array}$ & $\mathbf{t}$ & df & $\mathbf{p}$ & Sig. \\
\hline Baseline & $37.60 \pm 3.03$ & - & - & - & - & - & - \\
\hline 4 weeks & $39.57 \pm 3.13$ & $1.97 \pm 1.40$ & 0.26 & 7.69 & 29 & 0.000 & $\mathrm{HS}$ \\
\hline 8 weeks & $41.13 \pm 3.41$ & $3.53 \pm 2.31$ & 0.42 & 8.36 & 29 & 0.000 & $\mathrm{HS}$ \\
\hline 12 weeks & $42.37 \pm 3.02$ & $4.77 \pm 2.40$ & 0.44 & 10.87 & 29 & 0.000 & $\mathrm{HS}$ \\
\hline
\end{tabular}


As is evident from the table 5, the mean change \pm SD in HDL-C level with Rosuvastatin treatment was 1.97 \pm 1.40 , $3.53 \pm 2.31$ and $4.77 \pm 2.40$ at the end of 4,8 and 12 weeks respectively. The analysis of increase in mean HDL-C level at different time interval was found to be statistically highly significant $(\mathrm{P}<0.001)$ at 4, 8 and 12 weeks.

Table 6: Comparison of change in mean high density lipoprotein cholesterol (HDL-C) level in group B (T. Arjuna) patients

\begin{tabular}{|c|c|c|c|c|c|c|c|}
\hline Time interval & Mean \pm SD & Mean change \pm SD & SE Mean & t & df & p & Sig. \\
\hline Baseline & $42.70 \pm 7.44$ & - & - & - & - & - & - \\
\hline 4 weeks & $45.07 \pm 6.85$ & $2.37 \pm 2.20$ & 0.40 & 5.88 & 29 & 0.000 & HS \\
\hline 8 weeks & $46.13 \pm 6.66$ & $3.43 \pm 2.88$ & 0.53 & 6.52 & 29 & 0.000 & HS \\
\hline 12 weeks & $47.07 \pm 6.39$ & $4.37 \pm 2.76$ & 0.50 & 8.66 & 29 & 0.000 & HS \\
\hline
\end{tabular}

As is evident from the table 6 , the mean change \pm SD in HDL-C level with T.arjuna treatment was $2.37 \pm 2.20$, $3.43 \pm 2.88$ and $4.37 \pm 2.76$ at the end of 4,8 and 12 weeks respectively. The analysis of increase in mean HDL-C level at different time interval was found to be statistically highly significant $(\mathrm{p}<0.001)$ at 4,8 and 12 weeks.

Table 7: Comparison of change in mean high density lipoprotein cholesterol (HDL-C) level between group A (Rosuvastatin) and group B (T. Arjuna) patients

\begin{tabular}{|c|c|c|c|c|c|c|c|c|c|}
\hline $\begin{array}{c}\text { Time } \\
\text { interval }\end{array}$ & Group & $\begin{array}{l}\text { Mean } \pm \\
\text { SD }\end{array}$ & $\begin{array}{c}\text { Mean change } \\
\pm \text { SD }\end{array}$ & $\begin{array}{c}\text { Mean } \\
\text { difference }\end{array}$ & $\begin{array}{c}\text { SE } \\
\text { difference }\end{array}$ & $\mathbf{t}$ & df & $\mathbf{p}$ & Sig. \\
\hline \multirow[t]{2}{*}{ Baseline } & $\mathrm{A}$ & $37.60 \pm 3.03$ & - & - & - & - & - & - & - \\
\hline & $\mathrm{B}$ & $42.70 \pm 7.44$ & - & - & - & - & - & - & - \\
\hline \multirow{2}{*}{$\begin{array}{c}\text { After } \\
4 \text { weeks }\end{array}$} & $\mathrm{A}$ & $39.57 \pm 3.13$ & $1.97 \pm 1.40$ & \multirow[t]{2}{*}{0.40} & \multirow[t]{2}{*}{0.48} & \multirow[t]{2}{*}{0.84} & \multirow[t]{2}{*}{58} & \multirow[t]{2}{*}{0.405} & \multirow[t]{2}{*}{ NS } \\
\hline & B & $45.07 \pm 6.85$ & $2.37 \pm 2.20$ & & & & & & \\
\hline \multirow{2}{*}{$\begin{array}{c}\text { After } \\
8 \text { weeks }\end{array}$} & A & $41.13 \pm 3.41$ & $3.53 \pm 2.31$ & \multirow[t]{2}{*}{0.10} & \multirow[t]{2}{*}{0.67} & \multirow[t]{2}{*}{0.15} & \multirow[t]{2}{*}{58} & \multirow[t]{2}{*}{0.883} & \multirow[t]{2}{*}{ NS } \\
\hline & B & $46.13 \pm 6.66$ & $3.43 \pm 2.88$ & & & & & & \\
\hline \multirow{2}{*}{$\begin{array}{c}\text { After } \\
12 \text { weeks }\end{array}$} & $\mathrm{A}$ & $42.37 \pm 3.02$ & $4.77 \pm 2.40$ & \multirow[t]{2}{*}{0.40} & \multirow[t]{2}{*}{0.67} & \multirow[t]{2}{*}{0.59} & \multirow[t]{2}{*}{58} & \multirow[t]{2}{*}{0.552} & \multirow[t]{2}{*}{ NS } \\
\hline & B & $47.07 \pm 6.39$ & $4.37 \pm 2.76$ & & & & & & \\
\hline
\end{tabular}

Table 7 and fig. 3: shows increase in mean HDL-C level in group B (T. Arjuna) as compared to group A (Rosuvastatin) was more $(2.37 \pm 2.20$ vs $1.97 \pm 1.40)$ at 4 weeks but was slightly less $(3.43 \pm 2.88$ vs $3.53 \pm 2.31)$ and $(4.37 \pm 2.76$ vs $4.77 \pm 2.40)$ at 8 and 12 weeks. The difference between both the groups was statistically non significant ( $\mathrm{p}>0.05)$ at 4,8 and 12 weeks.

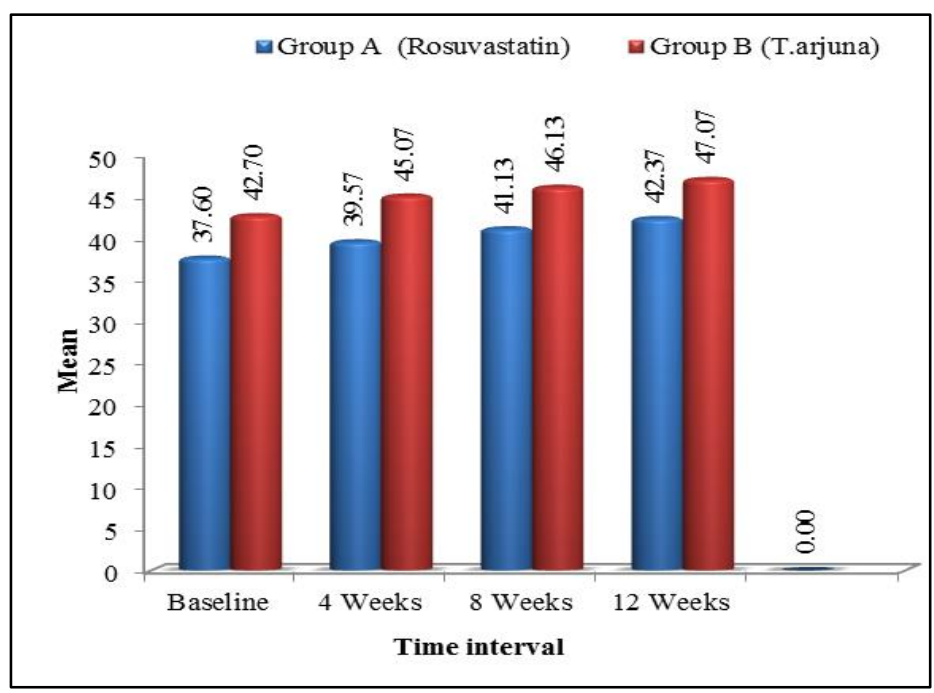

Fig. 3: Change in mean High density lipoprotein cholesterol level 


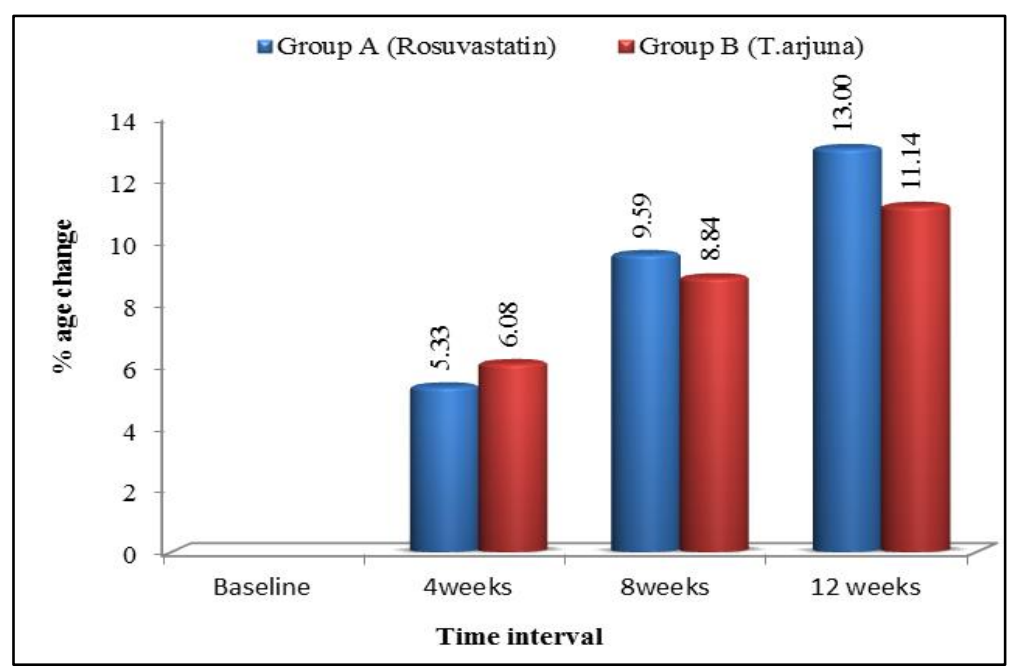

Fig. 4: Percentage change in mean High density lipoprotein cholesterol level

While increase in percentage mean HDL-C level in group B (T.arjuna) as compared to group A (Rosuvastatin) was more $(6.08 \pm 6.49 \%$ vs $5.33 \pm 3.99 \%)$ at 4 weeks but was slightly less $(8.84 \pm 8.71 \%$ vs $9.59 \pm 6.50 \%)$ and $(11.14 \pm 8.43 \%$ vs $13.00 \pm 7.28 \%)$ at 8 and 12 weeks. The difference between both the groups was statistically non significant ( $p>0.05)$ at 4,8 and 12 weeks.

\section{Discussion}

Hyperlipidemia, the disorders of lipid metabolism have been ranked as one of the greatest risk factors contributing to the prevelance and severity of atherosclerosis, stroke and CHD. Hyperlipidemia is characterised by elevated serum total cholesterol, low density lipoprotein, very low density lipoprotein cholesterol and decreased high density lipoprotein levels. Therefore the treatment of hyperlipidemia may reduce the risk of developing ischemic heart disease (IHD). Presently existing hypolipidemic drugs have been associated with some side effects. The herbal treatment for hypercholesterolemia has no side effect and relatively cheap. ${ }^{12}$

In the view of previous reports on efficacy of T.arjuna, the present study was designed evaluating and comparing the hypolipidemic efficacy of Terminalia arjuna with Rosuvastatin in patients of dyslipidemia. The results revealed that Tg and HDL-C levels are significantly affected by both the drugs (T.arjuna and Rosuvastatin).
In our study T.arjuna leads to greater reduction in percentage mean $\mathrm{Tg}$ level than Rosuvastatin ($15.16 \pm 12.24 \%$ vs $-7.81 \pm 3.55 \%),(-22.49 \pm 15.05 \%$ vs $14.78 \pm 5.84 \%)$ and $(-26.80 \pm 14.75 \%$ vs $-20.55 \pm 7.41 \%)$ at 4,8 and 12 weeks respectively. The difference between both the groups was statistically significant $(p<0.05)$ at 4,8 and 12 weeks, While increase in percentage mean HDL-C level in T.arjuna group as compared to Rosuvastatin group was more $(6.08 \pm 6.49 \%$ vs $5.33 \pm 3.99 \%)$ at 4 weeks but was slightly less $(8.84 \pm 8.71 \%$ vs $9.59 \pm 6.50 \%)$ and $(11.14 \pm 8.43 \%$ vs $13.00 \pm 7.28 \%)$ at 8 and 12 weeks. The difference between both the groups was statistically non-significant ( $p>0.05$ ) at 4,8 and 12 weeks.

Gupta et $\mathrm{al}^{13}$ conducted a clinical trial of 30 days duration, in which they compared the antioxidant and hypocholesterolemic effects of $500 \mathrm{mg}$ per day T.arjuna tree bark powder with placebo. They found that HDL-C level and Tg level did not change significantly. The present study of showed significant decrease in mean Tg level $(-26.80 \pm 14.75 \%)(\mathrm{p}<0.001)$ while mean HDL-C level was increased significantly $(11.14 \pm 8.43 \%)(\mathrm{p}<0.001)$. Longer study duration and higher dose of T.arjuna used may have resulted in better outcome in the present study.

Dwivedi and Agarwal $^{14}$ in a clinical trial of 3 months, studied the effect of bark powder of T.arjuna on HDL-C in patients of angina. The dose given was $500 \mathrm{mg}$ twice daily. It was found that T.arjuna increased HDL-C from $39.92 \pm 10.90$ to $44.00 \pm 11.70$, 
but was not statistically significant. They observed that increase in HDL-C was associated with improvement in coronary ischemia. The present study was also, showed increase in mean HDL-C level from $42.70 \pm 7.44$ to $47.07 \pm 6.39$ with percentage increase of $11.14 \%$. These results are comparable with the results of above trial.

Kumar et $\mathrm{al}^{15}$ in a clinical trial of 3 weeks, evaluated the safety and efficacy of T.arjuna bark powder in dyslipidemic patients. The dose used was 5 gm per day and it was found that there was a significant reduction in the serum levels of $\mathrm{Tg}$ $(\mathrm{p}<0.01)$ and significant elevation $(\mathrm{p}<0.05)$ in the HDL-C level. The percentage decrease in the levels of serum $\mathrm{Tg}$ was $9.9 \%$, and increase HDL-C was $8.1 \%$. The present study also showed significant decrease in mean Tg level $(-26.80 \pm 14.75 \%)(p<0.001)$ while mean HDL-C level showed significant increase $(11.14 \pm 8.43 \%)(\mathrm{p}<0.001)$. The better results in our study may be due to longer study duration.

The findings of clinical studies by Dwivedi and Agarwal ${ }^{14}$ and Kumar et $\mathrm{al}^{15}$ were in conformity with the present study which found that T.arjuna is an efficacious hypolipidemic agent causing marked decrease in serum Tg level as well as increase in HDL$\mathrm{C}$ levels.

Blasetto et $\mathrm{al}^{16}$ in a clinical trial of 12 weeks, found that Significant differences favouring Rosuvastatin $10 \mathrm{mg}$ was observed for HDL-C. The present study also showed, significant reduction in mean Tg level $(-20.55 \pm 7.41 \%)(\mathrm{p}<0.001)$ while mean HDL-C level was increased significantly $(13.00 \pm 7.28 \%)(\mathrm{p}<0.001)$ with Rosuvastatin.

Hunninghake et $\mathrm{al}^{17}$ in a clinical trial of 6 weeks, detected that Rosuvastatin 5-80 mg, produced significant mean reduction in $\mathrm{Tg}$ ranged from $-21 \%$ to $-46 \%(\mathrm{p} \leq 0.001)$. Significant increase in HDL-C was also observed. The present study also showed, significant reduction in mean $\mathrm{Tg}$ level $(-20.55 \pm 7.41 \%)$ $(\mathrm{p}<0.001)$, while mean HDL-C level was increased significantly $(13.00 \pm 7.28 \%)(\mathrm{p}<0.001)$. In the present study duration was longer and a single fixed dose of Rosuvastatin (10mg) was used.

Nissen et $\mathrm{al}^{18}$ in a clinical trial of 24 months duration, found that with Rosuvastatin $40 \mathrm{mg}$ per day, mean baseline HDL-C level $43.1 \mathrm{mg} / \mathrm{dl}$, increased to
$49.0 \mathrm{mg} / \mathrm{dl}$, an increase of $14.7 \%(\mathrm{p}<0.001)$. The present study also showed, mean baseline HDL-C level increased from $37.60 \pm 3.03$ to $42.37 \pm 3.02$, a mean increase of $13.00 \pm 7.28 \%$. Study by Nissen et al was of longer duration with higher dose of Rosuvastatin as compare to our study may have resulted in better outcome.

The findings of studies by Blasetto et al, ${ }^{16}$ Hunninghake et $\mathrm{al}^{17}$ and Nissen et $\mathrm{al}^{18}$ were in conformity with the present study which found that Rosuvastatin is also an efficacious hypolipidemic agent causing marked decrease in serum, $\mathrm{Tg}$ as well as increase in HDL-C levels.

\section{Conclusion}

12 weeks open randomized comparative study compared the effect of $\mathrm{T}$. arjuna with Rosuvastatin, on $\mathrm{Tg}$ levels and HDL-C levels in patients with dyslipidemia. It was found that both Rosuvastatin and T.Arjuna showed significant reduction in $\mathrm{Tg}$ level at all the visits. Improvement in Tg level was more with $\mathrm{T}$.Arjuna and when the effect of both the drugs on $\mathrm{Tg}$ level was compared, the difference was observed to be significant at the end of 4,8 and 12 weeks of starting the treatment. It was also found that patients of both the groups showed significant increase in HDL-C at all the visits. Rise in HDL-C level was slightly more with Rosuvastatin but on comparing the effect of both the drugs no statistically significant difference was observed.

It was thus concluded that both Rosuvastatin and Terminalia arjuna were effective hypolipidemic agents and caused significant decrease in $\mathrm{Tg}$ levels and increase in HDL-C levels but Terminalia arjuna had a slight edge over Rosuvastatin as it showed greater reduction in Tg levels and was found to be safe and well tolerated in dyslipidemic patients.

This conclusion is limited as the present study was of short duration with smaller sample size. Therefore Further, well-controlled multicentric clinical trials need to be conducted in large number of patients to explore the therapeutic potential of Terminalia arjuna.

\section{Abbreviations}

CVD: Cardiovascular disease, CHD: Coronary heart disease, IHD: Ischemic heart disease, CAD: Coronary 
artery disease, TC: Total cholesterol, Tg: Triglyceride, LDL-C: Low density lipoprotein cholesterol, HDL-C: High density lipoprotein cholesterol, T.arjuna: Terminalia arjuna, CK: Creatitine kinase, SD: Standard deviation.

\section{Source of Support}

None.

\section{Conflict of Interest}

None.

\section{References}

1. Fuster V, Kelly BB. In: Promoting cardiovascular health in the developing world: A critical challenge to achieve global health. Institute of medicine (IOM) committee on preventing the global epidemic of cardiovascular disease. Washington, D.C: The National academies press.2010;118.

2. Gupta S, Gudapati R, Gaurav K, Bhise M. Emerging risk factors for cardiovascular diseases: Indian context. Indian J Endocrinol Metab 2013;17(5):806-14.

3. Rissam HS, Kishor S, Trehan N. Coronary artery disease in young Indians-The missing link. J Indian Academy Clin Med 2001;2(3):128-32.

4. Achari V, Thakur AK. Association of major modifiable risk factors among patients with coronary artery disease-a retrospective analysis. J Asso Physician India 2004;52:1038.

5. Nelson RH. Hyperlipidemia as a risk factor for cardiovascular disease. Prim Care 2013;40(1):195-211.

6. Prakash V, Sehgal VK, Bajaj VK, Singh H. To Compare the effects of Terminalia arjuna with Rosuvastatin on Total cholesterol and Low density lipoprotein cholesterol. Int J Med and Dent Sci 2016;5(1):1056-66.

7. Maron DJ, Fazio S, Linton MF. Current perspectives on statins. Circ 2000;101:207-13. 337.

8. Bitzur R, Cohen H, Kamari Y, Harats D. Intolerance to statins:mechanisms and management. J Diab Care 2013;36(2):S325-30.

9. Sharma S, Sharma D, Agarwal N. Diminishing effect of arjuna tree (Terminalia arjuna) bark on the lipid and oxidative stress status of high fat high cholesterol fed rats and development of certain dietary recipes containing the tree bark for human consumption. Res Pharm 2012;2(4):22-30.

10. Maulik SK, Katiyar CK. Terminalia arjuna in cardiovascular Diseases: Making the transition from traditional to modern medicine in India. Curr Pharm Biotechnol 2010;10(8).

11. Kaur N, Shafiq N, Negi H, Pandey A, Reddy S, Kaur H et al. Terminalia arjuna in chronic stable angina: Systematic review and meta-analysis. Cardiol Res Pract 2014;2014.

12. Subramaniam S, Ramachandran S, Uthrapathi S, Gnamanickam VR, Dubey GP. Anti-hyperlipidemic and antioxidant potential of different fractions of Terminalia arjuna (Roxb) bark against PX-407 induced hyperlipidema. Indian J Exp Biol 2011;49(4):282-8.

13. Gupta R, Singhal S, Goyle A, Sharma VN. Antioxidant and hypocholesterolaemic effects of Terminalia arjuna treebark powder: A randomised placebo-controlled trial. $J$ Assoc Physician India 2001;49:231-5.

14. Dwivedi S, Agarwal MP. Antianginal and cardioprotective effects of Terminalia arjuna, an indigenous drug in coronary artery disease. J Asso Phys India 1994;42:287-9.

15. Kumar G, Srivastava A, Sharma SK, Gupta YK. Safety and efficacy evaluation of Ayurvedic treatment (Arjuna powder and Arogyavardhini Vati) in dyslipidemia patients: A pilot prospective cohort clinical study. Ayu 2012;33(2):197-201.

16. Blasetto JW, Stein EA, Brown WV, Chitra R, Raza A. Efficacy of rosuvastatin compared with other statins at selected starting doses in hypercholesterolemic patients and in special population groups. Am J Cardiol 2003;91(5A):3C-10C.

17. Hunninghake DB, Stein EA, Bays HE, Rader DJ, Chitra RR, Simonson SG et al. Rosuvastatin improves the atherogenic and atheroprotective lipid profiles in patients with hypertriglyceridemia. Coron Artery Dis 2004;15(2):115-23.

18. Nissen SE, Nicholls SJ, Sipahi I, Libby P, Raichlen JS, Ballantyne CM et al. Effect of very high-intensity statin therapy on regression of coronary atherosclerosis: The ASTEROID trial. JAMA 2006;295(13):1556-65.

How to cite this article: Prakash V. Study comparing the hypolipidemic effects of Terminalia arjuna with Rosuvastatin on triglyceride and high density lipoprotein- cholesterol levels. Int J Pharm Chem Anal 2019;6(4):127-35. 